Jurnal Artikel

\title{
Penentuan Nilai Efektivitas Kondensor Di PLTGU Blok 1-2 PT. Indonesia Power UPJP Priok
}

\author{
Didit Sumardiyanto $^{1 *}$, Aldi Januar ${ }^{2}$ \\ ${ }^{1,2}$ Fakultas Teknik, Universitas 17 Agustus 1945 Jakarta, Jakarta Utara, 14350 \\ *Email : didit.sumardiyanto@yahoo.co.id \\ *Corresponding author-Email : didit.sumardiyanto@yahoo.co.id
}

Artkel Info - : Received : 30 Jul 2020; Revised : 28 Aug 2020; Accepted: 30 Aug 2020

\begin{abstract}
Abstrak
(Kondensor merupakan salah satu komponen utama pada sistem yang bekerja mengubah uap menjadi air dan digunakan kembali. Kinerja dari suatu kondensor dapat dipengaruhi oleh laju perpindahan panas, tekanan vakum dan efektivitas. Tujuan penelitian ini adalah untuk mengetahui nilai efektivitas dan variabel yang mempengaruhi kinerja kondensor di PLTGU PT. Indonesia Power UPJP Priok. Metode penentuan nilai efektivitas menggunakan metode log mean temperature different (LMTD) dan number of transfer unit effectiveness $(N T U-\varepsilon)$. Pada hasil penelitian, perhitungan nilai efektivitas pada kondensor pertama sebesar $83,28 \%$, kondensor kedua sebesar $84,15 \%$ dan kondensor rata-rata sebesar $83,72 \%$. Variabel yang mempengaruhi adalah kapasitas rasio sebesar 0,01183, laju perpindahan kalor panas sebesar 2.046,9932 $k W$, LMTD sebesar 7,6416 $6^{\circ}$, jumlah satuan perpindahan sebesar 0,7996, dan tekanan vakum sebesar 0,04395. Sehingga dapat disimpulkan bahwa kondensor yang ada PT. Indonesia Power UPJP Priok masih mempunyai performa yang baik.
\end{abstract}

Kata kunci: kondensor, LMTD, efektivitas NTU

\begin{abstract}
Condenser is one of the main components in the system that works to convert steam into water and reuse it. The performance of a condenser can be influenced by heat transfer rate, vacuum pressure and effectiveness. This research was to determine the value of effectiveness and variables that influence the performance of the condenser at the PT. Indonesia Power UPJP Priok. The method of determining the value of effectiveness used the log mean temperature different (LMTD) method and the number of transfer unit - effectiveness $(N T U-\varepsilon)$. The results of research, the calculation of the effectiveness value on the first condenser was $83,28 \%$, the second condenser was $84,15 \%$ and the average condenser was $83,72 \%$. The influencing variable, capacity ratio was 0,01183, heat transfer rate was 2.046,9932 $\mathrm{kW}$, log mean temperature different was $7,6416^{\circ} \mathrm{C}$, the number of displacement units was 0,7996, and the vacuum pressure was 0.04395. So it can be concluded that the existing condenser PT. Indonesia Power UPJP Priok still has good performance
\end{abstract}

Keywords: condenser, LMTD, effectiveness of NTU

\section{PENDAHULUAN}

Kondensor merupakan salah satu komponen utama pada sistem PLTGU yang berfungsi untuk mengubah uap dari yang keluar dari turbin uap menjadi air untuk dipergunakan kembali. Kinerja dari kondensor berpengaruh terhadap efisiensi dari pembangkit listrik PLTGU. Salah satu masalah yang terjadi di kondensor adalah terjadi pengotoran pada jalur tube air laut yang disebabkan oleh kotoran yang terbawa oleh air laut, sehingga mengganggu proses pelepasan panas di dalam kondensor berkurang. Hal ini akan 
mengakibatkan penurunan efektivitas perpindahan kalor pada kondensor. Sehingga hal yang dilakukan saat melakukan perawatan pada kondensor adalah membersihkan tube pada kondensor tersebut agar tidak terjadi pelapisan yang dapat mengganggu proses perpindahan kalor pada kondensor.

Untuk mengetahui kondisi kondensor baik atau tidaknya salah satu caranya adalah dengan menghitung efektivitas dari kondensor tersebut. Ada beberapa faktor yang dapat mempengaruhi dalam kinerja kondensor diantaranya yaitu laju perpindahan panas, efektivitas dan tekanan vakum. Untuk mengetahui efektivitas dari kinerja kondensor digunakan metode log mean temperature different (LMTD) dan number of transfer unit - effectiveness $(\mathrm{NTU}-\varepsilon)$.

\section{KAJIAN PUSTAKA}

\subsection{Kondensor}

Kondensor merupakan alat penukar kalor (Heat Exchanger) yang berfungsi mengkondensasikan uap bekas dari turbin tekanan rendah (Low Pressure Turbine) menjadi titik-titik air (air kondensat) dan air yang terkondensasi menjadi air ditampung yang kemudian pada Hotwell. Selanjutnya air tersebut disirkulasikan kembali ke boiler (ketel uap) untuk diproses kembali menjadi uap. Di dalam kondensor terdapat siklus yang saling berkaitan, yaitu siklus fluida panas dari uap keluaran turbin tekanan rendah dan siklus air pendingin yang diperoleh dari air laut, yang mana keduanya saling bersilangan arah (cross flow). Uap bekas turbin tekanan rendah sebagai fluida panas dalam bentuk yang berada di luar pipa kondensor akan melepaskan kalor ke air pendingin yang melewati pipa (tube) di dalam kondensor sebagai fluida dingin.

Kondensor dengan menurunkan tekanan hilir atau menurunkan tekanan absolut di dalamnya, efisiensi instalasi meningkat dan aliran uap pun berkurang untuk suatu keluaran instalasi yang tetap.
Semakin rendah tekanan, semakin besar efek ini. Jadi penting sekali untuk menggunakan suhu air pendingin yang serendah mungkin (Fatkhurrahman, 2014).

\subsection{Analisa Perpindahan Panas dengan Metode Log Mean Temperature Different (LMTD)}

Metode ini digunakan untuk mencari temperatur rata-rata, yaitu dari temperatur inlet dan outlet dari fluida, pada pesawat penukar kalor. Maka untuk mendapatkan laju perpindahan panas, digunakan perumusan sebagai berikut (Holman, 1995):

$q=U \cdot A \cdot L M T D$

Dimana :

- $q$ : laju perpindahan panas (W);

- $U$ : overall heat transfer coefficient/ koefisien perpindahan kalor keseluruhan;

- $A$ : Luas total bidang permukaan perpindahan panas $\left(\mathrm{m}^{2}\right)$;

- LMTD : Perbedaan temperatur ratarata menyeluruh antara fluida panas dan fluida dingin $\left({ }^{\circ} \mathrm{C}\right)$

$$
L M T D=\frac{\left(T h_{\text {in }}-T c_{\text {out }}\right)-\left(T h_{\text {out }}-T c_{\text {in }}\right)}{\ln \frac{\left(T h_{\text {in }}-T c_{\text {out }}\right)}{\left(T h_{\text {out }}-T c_{\text {in }}\right)}} \ldots
$$

Dimana :

- $T c_{i n}$ : Temperatur fluida dingin masuk kondensor $\left({ }^{\circ} \mathrm{C}\right)$;

- $T c_{\text {out }}$ : Temperatur fluida dingin keluar kondensor $\left({ }^{\circ} \mathrm{C}\right)$;

- $T h_{\text {in }}$ : Temperatur fluida panas/uap masuk kondensor dari turbin tekanan rendah $\left({ }^{\circ} \mathrm{C}\right)$;

- $T h_{\text {out }}$ : Temperatur fluida panas keluar dari kondensor $\left({ }^{\circ} \mathrm{C}\right)$

Besar kalor yang dipindahkan dari fluida panas ke fluida dingin sama dengan yang diterima oleh fuida dingin dari fluida panas adalah :

$q=\dot{m} \times \mathrm{c}_{\mathrm{p}} \times \Delta T$

Dimana :

$q$ : perpindahan kalor $(\mathrm{kW})$;

$c_{p}$ : Kapasitas panas fluida $(\mathrm{kJ} /(\mathrm{kg} \cdot \mathrm{K}))$

$\dot{m}$ : massa aliran Uap (kg/s);

$\Delta T$ : Perbedaan temperatur fluida $\left({ }^{\circ} \mathrm{C}\right)$; 


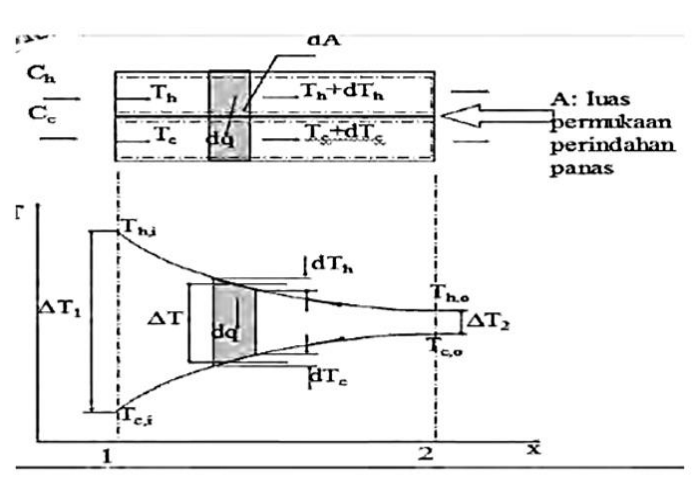

Gambar 1. Distribusi temperatur untuk Aliran Parallel (Incropera, 2007)
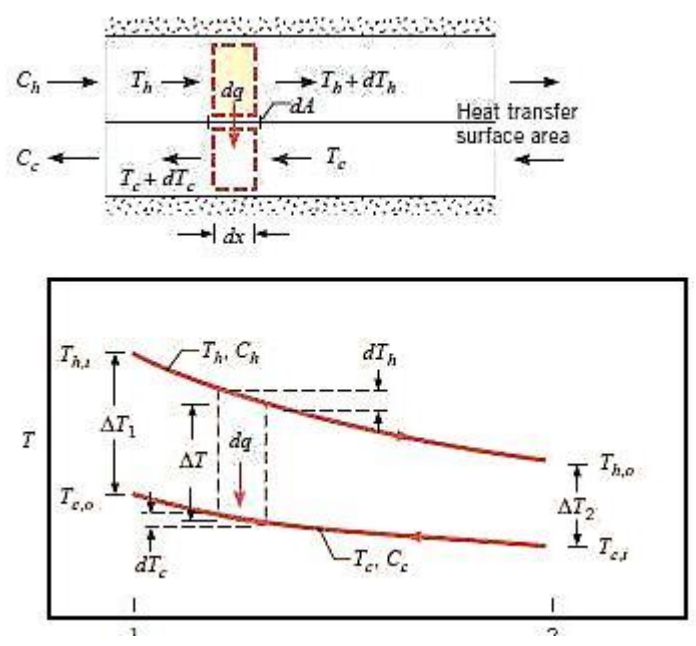

Gambar 2. Distribusi Temperatur untuk Aliran Berlawanan Arah

(Incropera , 2007)

\subsection{Analisa Perpindahan Panas dengan}

Metode Effectiveness Number of Transfer Unit (NTU)

Untuk metode NTU sendiri ialah bilangan tak berdimensi yang digunakan untuk menganalisis perpindahan panas pada suatu pesawat penukar kalor. (Holman, 1995):

$N T U=\frac{U \cdot A}{C \min }$.

Dimana :

Cmin : nilai terkecil yang diperoleh dari Cwater dan Csteam.

Effectiveness $(\varepsilon)$ ialah rasio atau perbandingan antara laju perpindahan panas maksimum yang dimungkinkan terjadi pada suatu heat exchanger.

Untuk kondensor tipe shell and tube dengan satu shell and two passes, menurut Holman (1995) menggunakan perumusan effectiveness sebagai berikut :

$$
\begin{aligned}
& \varepsilon=2\left\{1+\mathrm{C}+\left(1+\mathrm{C}^{2}\right)^{\frac{1}{2}} \times\right. \\
& \left.\frac{1+\exp \left[\left(-\mathrm{NTU}\left(1+\mathrm{C}^{2}\right)^{\frac{1}{2}}\right]\right.}{1-\exp \left[\left(-\mathrm{NTU}\left(1+\mathrm{C}^{2}\right)^{\frac{1}{2}}\right]\right.}\right\}
\end{aligned}
$$

Dimana :

C : Capacity ratio (rasio kapasitas);

\section{METODE PENELITIAN}

Data penelitian didapat dari sektor pembangkitan PLTGU Blok 1-2 PT. Indonesia Power UPJP Priok, Data yang diperoleh antara lain berupa data aktual yang mencakup temperatur inlet dan outlet air laut, vakum kondensor, Low Pressure Turbin Exhaust Temperature, Saturation Temperature, Cooling Water flow, steam flow dan data Spesifikasi Kondensor.

Data yang telah diolah, selanjutnya dipresentasikan dalam bentuk grafik yang nantinya akan dianalisis sesuai dengan bentuk grafik yang terjadi. Dimana analisa data dilakukan dengan bentuk grafik hubungan efektivitas kondensor terhadap perubahan tekanan vakum dan grafik hubungan NTU terhadap efektivitas kondensor. Dari analisa tersebut maka dapat diketahui pengaruh apa saja yang menyebabkan perubahan kinerja pada kondensor.

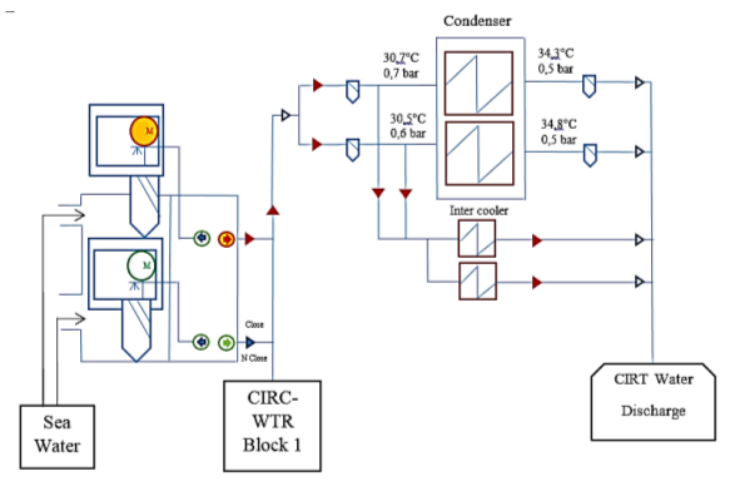

Gambar 3. Skema Kondensor Blok 1-2 PT. Indonesia Power UPJP Priok 


\section{HASIL DAN PEMBAHASAN}

\section{Tabel 1. Performa Kondensor PLTGU Blok 1-2 UPJP Priok pada tanggal 5 Mei 2020 pukul 11:10 WIB}

\begin{tabular}{|c|c|c|c|c|}
\hline \multirow{2}{*}{$\begin{array}{c}\text { Kinerja } \\
\text { Kondensor }\end{array}$} & \multirow{2}{*}{ unit } & \multicolumn{3}{|c|}{ Kondensor } \\
\hline & & 1 & 2 & Rata-Rata \\
\hline $\begin{array}{l}\text { Tekanan Vakum } \\
\text { Kondensor }\end{array}$ & Bar & 0,0442 & 0,0437 & 0,04395 \\
\hline $\begin{array}{l}\text { Laju Perpinda- } \\
\text { han Panas }\end{array}$ & $\mathrm{kW}$ & $2.046,9932$ & $2.046,9932$ & $2.046,9932$ \\
\hline LMTD & ${ }^{\circ} \mathrm{C}$ & 7,7023 & 7,5785 & 7,6416 \\
\hline NTU & & 0,7877 & 0,8116 & 0,7996 \\
\hline Efektivitas ( $\varepsilon$ ) & $\%$ & 83,28 & 84,15 & 83,72 \\
\hline
\end{tabular}

Hasil perhitungan efektivitas antara data kondensor secara aktual tidak mengalami perubahan yang sangat drastis pada kondensor 1 maupun dengan kondensor 2 yang memiliki selisih nilai efektivitas sangat rendah yaitu $0,87 \%$. Suatu kondensor dikatakan tergolong baik kinerjanya jika mempunyai nilai efektivitas sama atau tidak terlalu jauh antara kondensor saat berkerja dalam beberapa waktu dengan kondensor saat commissioning (komisioning). Dapat dikatakan kondensor yang ada pada blok 1-2 UPJP PT. Indonesia Power Priok masih tergolong baik dalam kinerjanya. Nilai efektivitas yang didapat pada kondensor 1 data aktual adalah 83,28\% sedangkan pada kondensor 2 data aktual nilai efektivitas yang didapat adalah $84,15 \%$ dan efektivitas dari rata-rata kondensor 1 dan 2 adalah 83,72\%.

Penurunan nilai efektivitas dapat dipengaruhi oleh nilai tekanan yang ada pada kondensor. Tekanan yang ada pada kondensor terbaca pada satuan bar. Semakin rendah tekanan yang dimiliki suatu kondensor maka nilai efektivitas yang dihasilkan akan semakin besar. Karena tekanan yang ada pada kondensor adalah tekanan vakum, maka tekanan tersebut dikonversi menjadi tekanan vakum. Semakin tinggi tekanan vakum maka nilai efektivitas yang dihasilkan semakin besar. Karena vakum merupakan suatu kondisi dari udara dimana tekanan udara dibawah tekanan atmosfer.

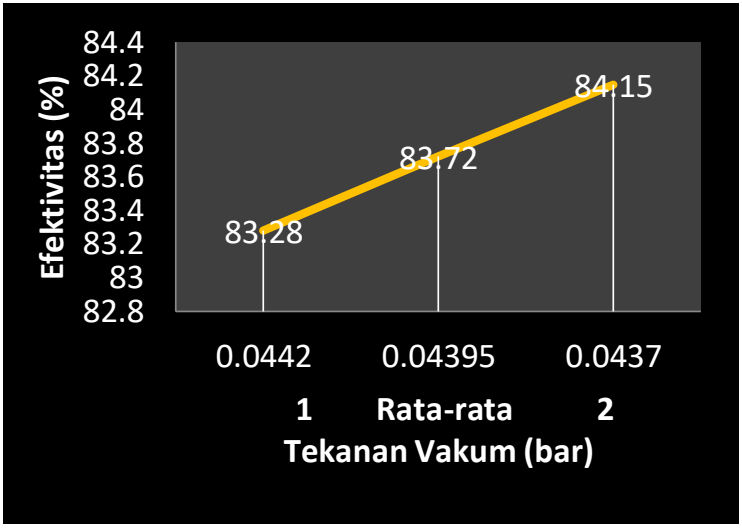

Gambar 4. Pengaruh Tekanan Vakum terhadap Efektivitas

Pada Gambar 4 diperoleh bahwa tekanan vakum adalah salah satu penyebab dari perubahan efektivitas kondensor. Hal ini dapat berkaitan dengan keadaan kondensor itu sendiri dimana salah satu penyebab naik turunnya tekanan yang ada pada kondensor yaitu proses kondensasi uap panas menjadi air kondensat. Vakum kondensat terjadi karena perbedaan density (densitas) antara uap panas dan air kondensat. Hal ini terjadi karena adanya proses kondensasi pada kondensor. Semakin cepat suatu kondensor melalukan proses kondensasi yang merubah uap panas dari Low Pressure (LP)/Tekanan Rendah Turbin menjadi condensate water (air kondensat) maka tingkat vakum akan semakin tinggi.

Adanya gas yang tidak terkondensasi dapat menyebabkan menurunnya tingkat kevakuman. Gas-gas yang tidak dapat terkondensasi ini merupakan gas-gas dari luar yang masuk pada kondensor (kebocoran udara). Karena kondensor didesain memiliki tekanan di bawah tekanan atmosfer maka akan memungkinkan ada udara yang masuk ke kondensor. Gas-gas ini menyelimuti permukaan luar pipa-pipa kondensor, hal ini akan menyebabkan berkurangnya kecepatan transfer panas antara uap panas dan pendingin air, sehingga kecepatan panas berkurang. Gas-gas yang menyebabkan kenaikan tekanan pada kondensor dapat menyebabkan penurunan efektivitas pengoperasian turbin uap. Karena adanya gas oksigen dalam 
kondensor maka dapat terjadinya korosif pada sekat-sekat kondensor. Untuk mempertahankan usia peralatan, maka oksigen tersebut dibuang. Salah satu cara yang dapat menghilangkan gas-gas ini adalah air removal equipment (alat penghilang udara) seperti adanya vacuum prime (vakum utama) yang ada di UPJP Priok ini. Vacuum prime sendiri merupakan pompa yang menghilangkan gas-gas penghambat kinerja kondensor.

Adanya fouling (endapan) yang mengotori tube-tube (pipa-pipa) kondensor sangat mungkin terjadi. Dapat diakibatkan kondensor pendingin air berasal dari air laut sehingga kemungkinan besar yang terjadi adalah banyaknya endapan kotorankotoran yang ikut masuk dan sebagian mengendap pada permukaan pipa-pipa dan bagian kondensor lainnya. Fouling (endapan) sendiri dibagi menjadi beberapa tipe yaitu fouling karena mikrobiologi, scale (skala), deposit, korosi, dan kotoran penyumbat pipa kondensor. Adanya endapan dapat menurunkan kinerja dari kondensor dan laju perpindahan panas pada kondensor akan berkurang.

Untuk menjaga kinerja kondensor dapat dilakukan dengan sering dilakukannya backwash (mencuci kembali) kondensor. Tujuan backwash sendiri adalah membuang kotoran-kotoran yang masuk dalam inlet kondensor. Untuk pembersihan pipa-pipa yang ada pada kondensor dapat dilakukan secara online dan offline. Saat online dilakukan pembersihan tube ketika dalam keadaan normal operasi dan offline ketika turbin uap dalam keadaan stand by (siap). Cleaning tube (pembersihan pipa) secara online dilakukan menggunakan bola tapproge atau biasa disebut ball cleaning condenser (bola pembersih kondensor). Fungsi ball cleaning (bola pembersih) ini adalah membersihkan permukaan pipa kondensor. Bola ini akan mengikuti aliran kondensor, dimana bola masuk pada water box inlet condenser dan keluar pada water box outlet kemudian bola-bola ini ditangkap oleh catcher atau penangkap dan diarahkan pada ball collecter atau pengumpul bola.

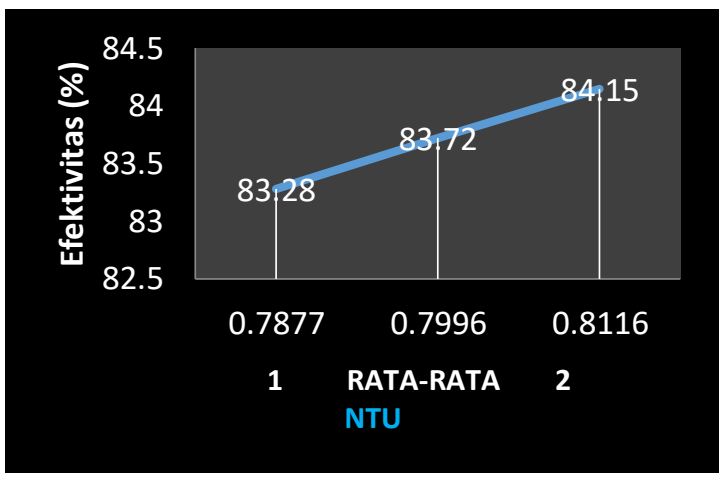

Gambar 5. Pengaruh Nilai NTU terhadap Nilai Efektivitas

Dari Gambar 5 dibuktikan bahwa semakin besar nilai NTU maka semakin besar pula nilai efektivitas yang dihasilkan.

\section{KESIMPULANA DAN SARAN}

\section{Kesimpulan}

Dari hasil analisis perhitungan yang telah dilakukan, dapat ditarik kesimpulan sebagai berikut:

a. Nilai efektivitas kondensor 1 di PLTGU PT. Indonesia Power UPJP Priok sebesar 83,28\%, efektivitas kondensor 2 sebesar 84,15\%, efektivitas kondensor rata-rata sebesar $83,72 \%$ dengan menggunakan metode log mean temperature different (LMTD) dan metode Effectiveness ( $\varepsilon$ ) number of transfer unit (NTU).

b. Variabel-variabel yang mempengaruhi besarnya efektivitas antara lain adalah kapasitas rasio sebesar 0,01183, laju perpindahan kalor panas sebesar $2.046,9932 \mathrm{~kW}, \Delta$ temperatur sebesar $7,6416^{\circ} \mathrm{C}$, numbers of transfer unit sebesar 0,7996, dan tekanan vakum sebesar 0,04395.

\section{Saran}

Kinerja kondensor akan menentukan kerja yang dihasilkan oleh pembangkit listrik dengan menggunakan turbin uap. Kinerja tersebut dipengaruhi salah satunya adalah kebersihan dinding-dinding penukar kalor. Untuk itu disarankan dilakukan 
pengecekan kebersihan secara berkala efisiensi pembangkit secara keseluruhan tetap terjaga dengan baik.

\section{DAFTAR PUSTAKA}

Cappenberg, A. D. Analisa Kinerja Alat Penukar Kalor Jenis Pipa Ganda. Jurnal Kajian Teknik Mesin, 1(2), 69.

Fatkhurrahman, M., Bono, Wiwik P. W. (2014). Analisis Kinerja Kondensor Terhadap Perubahan Tekanan Vakum di PT PLN (Persero) Sektor Pembangkitan PLTGU Cilegon. EKSERGI Jurnal Teknik Energi. Vol 10 (1) : 29-34.
Holman., J.P. (1995). Perpindahan Kalor. Edisi Keenam. Jakarta : Erlangga.

Incropera, F. P., David P. D., Theodore L., Bergman, dan Adrienne S. L. (2007). Fundamentals of Heat and Mass Transfer Sixth Edition. United Stated of America: Jhon Wiley \& Sons.

Soekardi., C. (2019). Teknik Perpindahan Energi Panas. Yogyakarta : Andi Offset.

Yohana., E., Bangkit., F., Nazaruddin., S., Mohamad., E. J., Indah., H. (2019). Analisis Pengaruh Temperatur dan Laju Aliran Massa Cooling Water Terhadap Efektivitas Kondensor di PT. Geo Dipa Energi Unit Dieng. ROTASI. Vol 21 (3) : 155-159. 